\title{
Emergency-Dependent Supply Decisions with Risk Perception and Price Control
}

\author{
Shaofu Du, Huifang Jiao, Rongji Huang, and Jiaang Zhu \\ School of Management, University of Science and Technology of China, Hefei 230026, China \\ Correspondence should be addressed to Jiaang Zhu; jaz@mail.ustc.edu.cn
}

Received 3 January 2014; Accepted 1 March 2014; Published 3 April 2014

Academic Editor: Fenghua Wen

Copyright (C) 2014 Shaofu Du et al. This is an open access article distributed under the Creative Commons Attribution License, which permits unrestricted use, distribution, and reproduction in any medium, provided the original work is properly cited.

This paper studies the impact of emergencies on the supplier's decision-making behaviors including production and information sharing in consideration of consumer risk perception, consumer loss aversion phenomenon, and government price control. The intensity of emergencies is sequential and emergencies can be divided into two types (positive or negative) according to their effect on demand. When emergencies have negative effect on demand, the supplier's sales will reduce and he would share information to the market. When emergencies have positive effect on demand, we find that when the price is under price cap the supplier will not share information to the market; when the price reaches price cap, the supplier will share a certain amount of information to the market. We were surprised to find that increasing demand is not always good for the supplier when there exist government price control and lost sales penalty, and information helps the supplier to effectively manipulate demand.

\section{Introduction}

Emergencies happen unexpectedly and cause disruptions and risks to the efficient management of the supply chain system. Managing risks in the modern environment is becoming increasingly challenging [1]. Risk itself can be broadly defined as disruption, vulnerability, uncertainty, disaster, peril, and hazard [2]. Recent studies in the supply chain domain have been focusing on the intensity of risk events and the availability of information, but few researchers study the managerial perceptions of risks which are important for supply chain risk management. It is still an unexplored area to study the subject's decision making behaviors of choosing the right risk strategy which is crucial and also is found to be commonly dominated by behavioral aspect of managers [2]. This paper studies the decision making behaviors including production and information sharing decisions for supplier in the presence of government price control when the stable market is shocked by emergencies which cause risks and presents a series of managerial insights about emergency management. We do so by assuming the intensity of emergency to be spatial and by considering consumer's loss aversion phenomenon, government's constant price cap, and the firm's information sharing strategies.
People typically exhibit greater sensitivity to losses than to equivalent gains when making decisions [3]. This is known as loss aversion in the prospect theory. Traditional risk neutral assumption is sometimes difficult to explain as consumers' loss aversion psychology phenomenon which will distort their consumption behavior. People with bounded rationality under the induced factors such as loss aversion show risk decision-making behaviors. We study the heterogeneous consumer decision-making behavior with the existence of behavioral risk which is significant for the supplier to obtain maximum profit by seeking the optimal pricing and production strategy in emergency. It is also believed that emergencies can abnormally promote or restrain demand. Earthquakes may lead to increasing demand for tents, but Toyota repeatedly recalling vehicles to fix problems which may cause danger definitely dents its reputational image, thus preventing consumers from taking Toyota into consideration when buying vehicles. Typically, earthquake in Japan 2011 caused a run on salt in China because of the nuclear crisis. Consumers believe that intake of salt, which contains iodine, could prevent sickness from nuclear radiation exposure. In our setting, we characterize consumers' utility function with different risk preferences under different types and intensities of emergencies and then derive the demand function 
according to the method of Hotelling model by solving the equilibrium of buying the products for the consumers.

In addition to personal preference, the amount of information also plays an important role in the boundedly rational consumer decision-making process within behavioral risks; especially in times of emergencies, information has a more pronounced boot capability on impacting individual behavior decision-making. Thus, information sharing is the primary means to deal with emergencies. We believe that supply chain information sharing in the process of eliminating the subjectively existed risk would impact the supplier's profit by influencing consumer individual behavioral decisions. The supplier circumvents the loss and earns the maximum benefit through information sharing when emergencies happen; thus, information sharing becomes an essential part of the supplier's strategy space to tackle emergencies.

The impact of emergencies on demand is bidirectional (positive or negative), which depends on the types of emergencies and we assume the intensity of emergencies to be spatial. Emergencies brought about a change in consumer behavior that affects the effectiveness of the consumer perception of the product. These effects tend to be a serious disturbance to the market and break the existing equilibrium state of the market. In order to avoid losses, vendors often choose to release the information available to reduce the disturbance of risk.

It is with those main assumptions above that we explore the emergency-dependent supply decisions with risk perception and price control. We derive the optimal supply and information sharing decisions and show that the supplier would release all information to eliminate risks to reduce losses when the emergencies have negative impact on the market. Intuitively the supplier has no incentive to release information to suppress consumer demand when positive risk occurs, but due to the existence of shortage costs and government price controls the supplier will share some information in order to maximize their profits. Due to the objective existence of shortage cost and price controls, the supplier's decision-making process becomes complicated, but the supplier's strategy space is broadened and full of management revelation, which is the main focus in this paper.

The paper is organized as follows: In Section 2, we systematically review related literature. The basic model is described in detail in Section 3. In Section 4, we analyze the supplier's decision making behaviors under different types of emergencies. In Section 5, we bring out extension analyses in the supplier's information strategies and the effects of government price control. The numerical examples are presented in Section 6. Conclusions and Discussions are explored in Section 7. Acknowledgements and Appendices will be given at last.

\section{Literature Review}

When emergency occurs, it not only brings objective risk but also changes people's subjective perception about the risk. It has long been recognized that there is considerable heterogeneity in individual risk taking behavior. Bruhin [4] presents a parsimonious characterization of risk taking behavior by estimating a finite mixture regression model for three different experimental data sets, two Swiss and one Chinese. Within consumer psychology, Dholakia [5] presents that both product involvement and perceived risk are viewed to be motivational constructs, influencing subsequent consumer behaviors such as information search and dissemination, as well as extensiveness of the decision-making process. Alessandri [6] explores the impact of perceived risk on the procedural rationality of the decision process and the findings suggest an inverted-U shaped relationship between perceived risk and procedural rationality. These papers only examine people's risk taking behaviors; they have not further discussed how the risk taking behaviors influence the market. Chen and Yano [7] considers a manufacturer-retailer supply chain for a seasonal product whose demand is weather sensitive, showing that public information and communication are important means of dealing with crisis. Yang et al. [8] studied a manufacturer that faces a supplier privileged with private information about supply disruptions and investigated how risk-management strategies of the manufacturer change and examine whether risk-management tools are valuable in the presence of such asymmetric information. These two papers study the supply chain members' risk taking behaviors; they have not further discussed how consumer risk taking behaviors influence the supplier's decision-making process under emergencies. In our paper, consumer risk taking behaviors are reasonably considered when deriving demand which significantly affects the supplier's decisions.

Another keyword in our paper is loss aversion. Behavioral economics reveals the existence of bounded rationality which is considered into the analysis framework; Kahneman and Tversky [9] put forward the concept of loss aversion as an important component of prospect theory. Compared to the traditional perfect rationality assumption, prospect theory believes that loss aversion phenomenon exists in the decision making process; namely, losses and disadvantages have greater impact on preferences than gains and advantages. Implications of loss aversion for economic behavior are considered [10]. Prospect theory successfully explains the phenomenon of bounded rationality and has been proven in scientific experiments; Abdellaoui et al. [11] put forward nonparametric methods to estimate loss aversion. In addition, many loss aversion issues are studied through designing of specific experiments [12-14] and have been utilized in areas such as the labor supply [15], asset portfolios [16], and consumer decision [17].

Considering loss aversion phenomenon within the supply chain domain is significant. Many recent papers study the impact of loss aversion phenomenon in supply chain performance and coordination comparing to the traditional case. Qi et al. [18] investigate a one-supplier-one-retailer supply chain that experiences a disruption in demand during the planning horizon and use wholesale quantity discount policies to achieve maximum profit. Gan et al. [19] study the loss aversion of agents in the supply chain coordination. Wang and Webster [20] study the problem of loss aversion in newsvendor model. Schweitzer and Cachon [21] design two experiments to investigate newsvendor decisions across 
different profit conditions. Results from these studies demonstrate that choices systematically deviate from those that maximize expected profit. In addition, supply chain inventory management [22], supply chain coordination contracts [23], and other issues under loss aversion perspective were also studied. However, the majority of the papers ignore consumers' loss aversion and its impact on demand which is mainly considered in our paper.

The distribution of corporate profits and social welfare benefits is levered by price controls of government or other regulatory authorities in order to prevent firms profiteering from raising prices by taking advantages of emergencies. Marshall et al. [24] systematically analyze the environment under uncertainty and present that optimal regulated prices were determined based on corporate earnings ratio and price ranges. Cowan [25] examines the effects of regulation in allocating price risk between consumers and shareholders and finds that there exists a tradeoff between risk allocation and allocative efficiency. It is because of the existence of price controls that the producers would rather have a stock shortage cost burden than continue to expand production to meet the needs of society, and the existence of this phenomenon enriches the space of the manufacturer's decisions. In our paper, we presumably consider the government price control to be constant and then analyze the supplier's decision making under the price cap.

Emergencies cause disruptions to the market through abnormally changing demand, thus significantly affecting the supplier's decision making behaviors. However, the supplier can use information as a tool to manipulate demand because disclosure and communication of information are important means to appease consumers' gloomy perception about the market. Thus, information has a significant impact on supply chain parties. Information sharing has long been studied by researchers. Faisal et al. [26] stated information sharing as a prerequisite for trust and current models for SCM agree that the sharing of business information is a crucial element, which binds supply chains together from end-to-end and increasing the visibility of demand information across supply chain reduces the risks. Li [27] examines the incentives of firms to share information in a two-level supply chain, where there are an upstream firm and many downstream firms, and also investigates the impact of vertical information sharing on the total supply chain profits and social benefits. We adopt the conclusions of these papers and present some arguable assumptions about how information affects people's perceptions to find out the supplier's optimal information sharing strategies.

\section{Models}

We consider a market, where there exists a monopoly manufacturer who sells a single kind product to end consumers, and the demand for this certain product is sensitive to emergencies. Supply chain emergency usually interrupts the harmonious operation of supply chain. Risk can be defined as the potential for unwanted negative consequences that arise from an event or activity. Risk itself can be termed
TABLE 1: Consumers' utility in the stable market.

\begin{tabular}{lcc}
\hline Consumers' choice & Purchase & Leave \\
\hline Probability of need $(\theta)$ & $r-p$ & $p-r$ \\
Probability of no need $(1-\theta)$ & $-p$ & 0 \\
Consumers' utility & $\theta(r-p)-(1-\theta) p$ & $\theta(p-r)$ \\
\hline
\end{tabular}

as disruption, vulnerability, uncertainty, disaster, peril, and hazard [28]. Emergencies (natural and man-made) would be a huge shock to the market. Suppose the intensity of emergencies to be sequential; the higher the intensity of the emergencies, the greater the impact would be. Consumers' behaviors are also distorted by their risk perception; this distortion will be worsened by lacking information. Thus, the demand is either strengthened or weakened by different types of emergencies. There are many examples of emergencies abnormally promoting or restraining demand, such as that earthquakes may lead to increasing demand to tents and that the Toyota recall crisis precipitously may damage Toyota's corporate brand reputation. In order to depict the bidirectional influence of the emergencies on demand, we denote the intensity of emergencies as $s$, which varies in the real number field; positive $s$ represents the types of emergencies which strengthen consumers' demand for a particular product, and, otherwise, negative $s$ represents the opposite effect.

3.1. Demand Function. We assume that consumers hold homogenous perception for the product in different market situations; this perception should be determined by their mental coding of combinations of gains and losses which decides how much they need the product. This perception also changes according to their emotions and expectation of the market. In a stable market, consumers' perception of needing the product is $\theta(0 \leq \theta \leq 1)$ under the retail price $p$. Denote $r$ as the common valuation for the product which should satisfy $r>p$. Note that when consumers buy the product which is not required, their utility should be the loss they paid for getting it which is $p$ in our consideration. We denote consumers' utility as $u$, which depends on probability of need $\theta$, price $p$, and common valuation for the product $r$ as described in Table 1.

Consumers are uniformly distributed in the segment $[0,1]$; the market scale is $D$. Following Hotelling's classical model [29], we assume that each consumer is characterized by a location $x$ in the segment $[0,1]$ and consumers incur a linear transportation cost, $r . x$ is a key factor to measure the consumer's willingness of buying the product; that is, the bigger $x$ means more transportation cost and then less willingness for the consumers to buy the products. Since the market is covered in equilibrium, we can derive the demand function by finding the location of the indifferent consumer $x_{D}$, which is given by

$$
\begin{gathered}
{[\theta(r-p)-(1-\theta) p]-x_{D} r=\theta(p-r)} \\
\Longrightarrow x_{D}=\frac{2 \theta r-p(1+\theta)}{r} .
\end{gathered}
$$


Consumers who locate in the segment $\left(0, x_{D}\right)$ are willing to purchase the product, while those who locate in $\left(x_{D}, 1\right)$ will leave the market, recalling that the market scale is $D$, so the realized demand $d_{0}$ should be

$$
d_{0}=D x_{D}=D \frac{2 \theta r-p(1+\theta)}{r} .
$$

When emergencies happen, the market would be shocked greatly. Consumers' perception about how much they like or dislike the product would be exaggerated; in other words, their decision making processes are influenced by the emergencies because of their bounded rationality and lack of information. Under the volatile market environment influenced by emergencies, consumers' perception about their willingness to buy the product changes from stable $\theta$ to $f(0 \leq f \leq$ $1)$; $f$ is either bigger or smaller than $\theta$ depending on the type of emergency and its effect on consumers' perception. Suppose the intensity of emergencies to be sequential; we denote the intensity of emergencies as $s$, which varies in the real number field; positive $s$ represents the types of emergencies which strengthen consumers' demand for a particular product, and, otherwise, negative $s$ represents the opposite. Prospect theory believes that loss aversion phenomenon exists in the decision making process; namely, losses and disadvantages have greater impact on preferences than gains and advantages. People typically exhibit greater sensitivity to losses than to equivalent gains when making decisions [3]. We introduce positive utility correction parameters $k_{1}$ and $k_{2}$ to capture consumers' loss aversion psychological phenomenon. Obviously, $f, k_{1}$, and $k_{2}$ are also correlated with the amount of information which will be discussed in Section 5 , and we assume those three to be constant parameters in this section. We introduce Boolean variable $i$ to distinguish the effect of the specific emergency, where $i=0$ for $s>0$ while $i=1$ for $s<0$.

The intensity of emergencies can influence the values of $k_{1}$ and $k_{2}$. As the absolute value of $s$ increases, $k_{1}$ and $k_{2}$ increase. When $s>0, i=0$, the specific emergency positively exaggerate consumers' demand for the product; thus, consumers' utility of leaving the market would be sharply lowered compared with the stable market, which is $\left(k_{1}+1\right)(p-r)$, for the reason of loss aversion. Similarly, when $s<0, i=1$, the specific emergency negatively decreases consumers' demand for the product; their utility of purchasing the product would be sharply lowered compared with the stable market, which is $-\left(k_{2}+1\right) p$. Table 2 depicts consumers' utility when the market is shocked by emergencies.

According to the assumption we give in the stable market, we can derive the demand function by finding the location of the indifferent consumer $x_{D}$, which is given by

$$
\begin{aligned}
f(r-p)-(1-f)\left(k_{2} i+1\right) p-x_{D} r \\
\quad=f(p-r)\left[k_{1}(1-i)+1\right] \\
\quad \Longrightarrow x_{D}=\frac{f(r-p)\left[k_{1}(1-i)+2\right]-(1-f)\left(k_{2} i+1\right) p}{r} .
\end{aligned}
$$

In order to ensure the validity of our model, the relationship between $r$ and $p$ should also satisfy

$$
\begin{aligned}
& f(r-p)-(1-f)\left(k_{2} i+1\right) p \\
& \quad \geq f(p-r)\left[k_{1}(1-i)+1\right] \\
& \quad \Longrightarrow r \geq\left(\frac{(1-f)\left(k_{2} i+1\right)}{f\left[k_{1}(1-i)+2\right]}+1\right) p
\end{aligned}
$$

where $i=0$ for $s>0$ while $i=1$ for $s<0$.

Thus, the realized demand function $d$ when the market is shocked by emergencies should be

$$
d=D x_{D}= \begin{cases}D \frac{2 f r+f k_{1} r-\left(1+f+f k_{1}\right) p}{r}, & s>0, \\ D \frac{2 f r-\left(1+f+k_{2}-f k_{2}\right) p}{r}, & s<0 .\end{cases}
$$

3.2. Equilibrium of the Stable Market. In this subsection, we will analyze the long-term equilibrium of the stable market, where the realized demand $d_{0}$ is equal to the supplier's production quantity $q$. The supplier's production cost per unit is $c$. Recalling to the demand function given in (2), the supplier's profit can be derived as

$$
\begin{aligned}
\pi & =p q-q c=D x_{D}(p-c) \\
& =\frac{D(p-c)[2 \theta(r-p)-(1-\theta) p]}{r} .
\end{aligned}
$$

The unique second derivative of the profit in (6) with respect to $p$ is expressed as follows:

$$
\frac{\partial^{2} \pi}{\partial p^{2}}=\frac{-2 D(1+\theta)}{r}<0
$$
by

Thus, we can derive the optimal price $p_{0}$ which is given

$$
p_{0}=\frac{2 \theta r+c(1+\theta)}{2(1+\theta)} .
$$

Accordingly, the optimal production $q_{0}$ under price $p_{0}$ appears as

$$
q_{0}=d_{0}=D x_{D}=D \frac{2 \theta r-c(1+\theta)}{2 r} .
$$

3.3. Profit Function When the Market Is Shocked by Emergencies. After emergencies shocked the market, the supplier would readjust his production plan which is made according to the long-term equilibrium. Due to the uncertainty caused by disruptions to the market demand, the supplier is faced with a more complicated operation optimization problem. The supplier's problem can be described as follows. Let $D$ be the market scale, and $d$ is the realized demand during the selling season which has been derived in Section 3.1 and given in (5). The price is $p$. The supplier's production cost in 
TABLE 2: Consumers' utility when the market is shocked by emergencies.

\begin{tabular}{lcc}
\hline Consumers' choice & Purchase & Leave \\
\hline Probability of need $(f)$ & $r-p$ & {$\left[k_{1}(1-i)+1\right](p-r)$} \\
Probability of no need $(1-f)$ & $-\left(k_{2} i+1\right) p$ & 0 \\
Consumers' utility & $f(r-p)-(1-f)\left(k_{2} i+1\right) p$ & $f(p-r)\left[k_{1}(1-i)+1\right]$ \\
\hline
\end{tabular}

the stable market is $c$. We assume that the supplier is faced with an increasing marginal cost when demand exceeds its production plan which is formed in a quadratic function, and the additional cost parameter is $\xi$. This is a reasonable and common assumption to describe the supplier's additional operation cost for unexpected expanded production. For each demand the supplier does not satisfy the supplier incurs a goodwill penalty cost $g$ [30]. The supplier earns $v(v<c$ and $v \leq p$ ) per unit unsold at the end of season, where $v$ is the net salvage value.

The supplier's profit function is

$$
\begin{aligned}
\pi= & p q-q_{0} c-\left(q-q_{0}\right)^{+} c-\xi\left[\left(q-q_{0}\right)^{+}\right]^{2} \\
& +\left(q_{0}-q\right)^{+} v-(d-q)^{+} g
\end{aligned}
$$

where $q_{0}$ is the long term equilibrium production which is supposed to be produced before the emergencies happen and $q$ is the decision variable which the supplier would supply to the market after emergencies shock the market during the same selling season. Thus, $(d-q)^{+} g$ represents the lost sales penalty cost, $\left(q-q_{0}\right)^{+} v$ is the net leftover value, and $\xi\left[\left(q-q_{0}\right)^{+}\right]^{2}$ is the additional operation cost of the supplier, and $(A)^{+} \equiv \max \{0, A\}$.

\section{Analysis}

In this section, we will analyze the supplier's optimal production with emergencies attacking the market under price cap which is controlled by the government. In order to prevent the supplier from seeking excessive profits by taking advantage of the consumer panic caused by emergencies, the government will set a price cap $\bar{p}$ to the emergency required products. Obviously, price cap $\bar{p}$ should satisfy

$$
\bar{p}>p_{0}=\frac{2 \theta r+c(1+\theta)}{2(1+\theta)} .
$$

To facilitate analysis, we introduce $d_{T}$, which represents the actual demand when price reaches $\bar{p}$. Recalling to (5), we have

$$
d_{T}=D \frac{f(r-\bar{p})\left[k_{1}(1-i)+2\right]-(1-f)\left(k_{2} i+1\right) \bar{p}}{r},
$$

where $i=0$ for $s>0$ while $i=1$ for $s<0$.

When $s<0$, the supplier may purposefully reduce supply to the market and improve price until it reaches price cap. It is of no doubt that the price is very likely to reach price cap and this is exactly the case that the government needs to control when $s>0$. In the case $s>0$, we can imagine this circumstance in which the supplier achieves his optimal profit under the price cap $\bar{p}$; that is, the supplier's marginal net profit is zero and we assume the optimal supply is $q_{T}$. It is not hard to find that the supplier has no incentive to produce more even if there exists lost sales penalty when $d_{T} \geq q_{T}$, because more production means negative marginal profit. Analogously, the supplier would increase production to satisfy demand when $d_{T}<q_{T}$, because it is still profitable. By assuming $q \geq q_{0}$ (when $s>0$, the supply quantity $q$ will always be higher than $q_{0}$ which is proved in Appendix B) and substituting $p=\bar{p}$ to (10) we can derive the optimal supply $q_{T}$ :

$$
q_{T}=\frac{\bar{p}-c+g+2 \xi q_{0}}{2 \xi} .
$$

Then, the profit function in (10) can be rewrite as

$$
\pi= \begin{cases}p q-q_{0} c+\left(q_{0}-q\right) v, & \text { if } q<q_{0} \\ p q-q c-\xi\left(q-q_{0}\right)^{2} & \\ -(d-q) g, & \text { if } q \geq q_{0}, d_{T} \geq q_{T} \\ p q-q c-\xi\left(q-q_{0}\right)^{2}, & \text { if } q \geq q_{0}, d_{T}<q_{T}\end{cases}
$$

4.1. Decision-Making of the Supplier under Negative Emergency Impact. In this subsection, we investigate the supplier's optimal production decisions with negative influence of the emergencies to the market, which indicates that the intensity of emergencies is negative, $s<0$. With negative $s$, consumers' perception about how much they need the product should be lower than the normal case; this indicates that $f<\theta$, the actual market demand will go down compared with that in the stable market, and the supplier has sufficient capability to satisfy demand; $q$ is the supplier's real production/sales and in this case it is sales quantity during the selling season. Based on the demand function in (5) and profit function in (14), the profit function in this situation should be

$$
\pi=p q-q_{0} c+\left(q_{0}-q\right) v, \quad q<q_{0}
$$

where $q=d=D\left(2 f-(p / r)\left(1+f+k_{2}-f k_{2}\right)\right)$ and $f<\theta$.

Note that in (15), we have excluded the situation when $q \geq q_{0}$; that is, the supplier must have no incentive to expand production under negative emergency impact. In Appendix A we show the proof. According to (15), the supplier will produce to satisfy demand; thus $q=d$; $d$ is the realized demand. Then, we can solve the optimal conditions of the supplier.

The unique second derivative of the profit function in (15) with respect to $p$ is expressed as follows:

$$
\frac{\partial^{2} \pi}{\partial p^{2}}=\frac{-2\left(1+f+k_{2}-f k_{2}\right) D}{r}<0 .
$$


Thus, the supplier's optimal decision-makings can be derived by solving the first order optimal conditions which are

$$
\begin{aligned}
p^{*} & =\frac{2 f r+v\left(1+f+k_{2}-f k_{2}\right)}{2\left(1+f+k_{2}-f k_{2}\right)} ; \\
q^{*} & =D f+\frac{D\left(f\left(k_{2}-1\right)-k_{2}-1\right) v}{2 r} ; \\
\pi^{*} & =\frac{D\left(v+k_{2} v+f\left(v-2 r-k_{2} v\right)\right)^{2}}{4\left(f\left(k_{2}-1\right)-k_{2}-1\right) r}-4 q_{0}(c-v) .
\end{aligned}
$$

4.2. Decision-Making of the Supplier under Positive Emergency Impact. Now we proceed to analyze the supplier's decisionmaking when emergencies generate positive influence to the market. In this case, consumers show higher perception about how much they need the product compared with that in the stable market, which indicates that $f>\theta$, and the actual demand will increase. But the supplier's production may or may not guarantee market demand which mainly depends on the relationships between government price control, additional production cost, and lost sales penalty cost. The supplier's real supply to the market is $q$. Then, the supplier's profit function in this situation should be

$$
\pi= \begin{cases}p q-q c-\xi\left(q-q_{0}\right)^{2}-(d-q) g, & \text { if } q \geq q_{0}, d_{T} \geq q_{T} \\ p q-q c-\xi\left(q-q_{0}\right)^{2}, & \text { if } q \geq q_{0}, d_{T}<q_{T}\end{cases}
$$

Note that (18) is parts of (14) when $q \geq q_{0}$. We have excluded the situation of $q<q_{0}$; that is, the supplier must have no incentive to reduce supply under positive emergency impact. In order to manipulate price and gain more profits, the supplier may purposefully reduce product supply $q$ which is less than $q_{0}$, but in Appendix B, we have proved that the supplier will not reduce supply in detail. Now we proceed to discuss the optimal conditions for the supplier to manage disruptions caused by emergency, in which the supplier would produce extra quantity to satisfy the increased demand. Recalling that when $d_{T}<q_{T}$, it is still profitable for the supplier to produce/sell more to the market because the actual demand of the market $d_{T}$ under price cap $\bar{p}$ is lower than the critical production $q_{T}$ where the supplier's net profit is zero. In this case $q=d$, and the profit function is described as follows:

$$
\pi=p q-q c-\xi\left(q-q_{0}\right)^{2}
$$

In this case, the supplier's optimal production decisions need to be divided into two sets, because the price may exceed price cap. In order to illustrate the two different situations (price under price cap, price at price cap), we further denote a couple of variables ( $\left.p_{\text {no cap }}, q_{\text {no cap }}\right)$, which stand for the supplier's optimal condition when there is no price cap to the market. Then, the supplier's optimal conditions are described as follows:

$$
\begin{gathered}
p^{*}=p_{\text {no cap }}, \quad q^{*}=q_{\text {no cap }} \text {, if } p_{\text {no cap }} \leq \bar{p} ; \\
p^{*}=\bar{p}, \quad q^{*}=D \frac{2 f r+f k_{1} r-\left(1+f+f k_{1}\right) \bar{p}}{r}, \\
\text { if } p_{\text {no cap }}>\bar{p}, d<q_{T} .
\end{gathered}
$$

When $p_{\text {nocap }} \leq \bar{p}$, the price cap is higher than the optimal price where the supplier can maximize profit. In this situation, the price cap has no biding effect to the supplier under certain degrees of intensity of the emergencies. Then, we can derive the supplier's optimal solutions. The unique second derivative of the profit function in (19) with respect to $q$ is expressed as follows:

$$
\frac{\partial^{2} \pi}{\partial p^{2}}=-\frac{2 D\left(1+f+f k_{1}\right)\left(r+D \xi\left(1+f+f k_{1}\right)\right)}{r^{2}}<0 .
$$

Thus, the supplier's optimal decision-making when $p_{\text {no cap }} \leq \bar{p}$ can be derived by solving the first order optimal conditions which are

$$
\begin{aligned}
p^{*} & =\frac{r\left(c m+f n r+2 m \xi\left(D f n-q_{0}\right)\right)}{2 m(r+D m \xi)} ; \\
q^{*} & =\frac{D\left(f n r+2 q_{0} m \xi-c m\right)}{2(r+D m \xi)} ; \\
\pi^{*} & =\frac{D(c m-f n r)^{2}-4 q_{0} m\left(c D m+\left(q_{0}-D f n\right) r\right) \xi}{4 m(r+D m \xi)}
\end{aligned}
$$

where $m=1+f+f k_{1}, n=2+k_{1}$.

When $p_{\text {nocap }}>\bar{p}$, the price cap will stop the price from increasing too high under some certain high intensity emergency. And when $d<q_{T}$, the supplier is willing to produce extra amount of products to satisfy demand because the lost sales penalty cost is lower than the additional production cost. In this case, the supplier's optimal decisions are pricing at price cap $\bar{p}$ and supplying at $d$ which are given in the following:

$$
\begin{gathered}
p^{*}=\bar{p} ; \\
q^{*}=D \frac{f r n-m \bar{p}}{r} ; \\
\pi^{*}=\frac{D r(\bar{p}-c)(f r n-m \bar{p})-\xi\left(D m \bar{p}-D f n r+q_{0} r\right)^{2}}{r^{2}} .
\end{gathered}
$$

Then, we discuss the situation when the supplier is willing to undertake lost sales penalty other than produce more to satisfy demand. Recalling that when $d_{T}>q_{T}$, the supplier has no incentive to produce more even if there exists lost sales penalty, which means that the actual demand is bigger than the supplier's production; that is, $d>q$, and the supplier will price his products at price cap $\bar{p}$ to gain more profits. 
The price is controlled under price cap $\bar{p}$ while the real demand of the market $d$ cannot be satisfied. Thus, the price cap $\bar{p}$ is a double-edged sword for the government to regulate price. In this case, the supplier's profit function should be

$$
\pi=\bar{p} q-q c-\xi\left(q-q_{0}\right)^{2}-(d-q) g .
$$

The unique second derivative of the profit in (24) with respect to $q$ is expressed as follows:

$$
\frac{\partial^{2} \pi}{\partial q^{2}}=-2 \xi<0 .
$$

Thus, the supplier's optimal decision-making can be derived by solving the first order optimal conditions which are

$$
\begin{gathered}
p^{*}=\bar{p} ; \\
q^{*}=\frac{\bar{p}-c+g+2 \xi q_{0}}{2 \xi} ; \\
\pi^{*}=\frac{r(g+\bar{p}-c)^{2}+4 \xi\left(q_{0} r(g+\bar{p}-c)+D g(\bar{p} m-f n r)\right)}{4 r \xi} .
\end{gathered}
$$

\section{Extensions}

In this section, we analyze the supplier's information sharing strategies under different types of influences to the market by different emergencies. Assume that the supplier has real, perfect, and nonredundant information about the market after emergencies happened, and the information is sequential. Denote $A$ as the perfect information that the supplier holds and $a$ as the supplier's decision variable on the amount of information he puts into the market. Then, $F(s, A)$ represents consumers' perception about how much they need the product under emergencies when they have perfect information about the real situation of the market, and demand would not be distorted by consumers' irrational valuation but only the objective distortion caused by emergencies. While in reality, consumers hardly can acquire real information, let alone perfect information, the supplier may manipulate demand by deciding how much information he chooses to put into the market. Consumers' behaviors are also distorted by their risk perception; this distortion will be worsened by lack of information. Thus, information plays an important role in mitigating consumers' loss aversion psychological phenomenon.

To facilitate analysis, some assumptions on the information structure are necessary.

Assumption 1. $\partial F(s, A) / \partial s>0$.

Assumption 2. $\partial f(s, a) / \partial a>0, s<0 ; \partial f(s, a) / \partial a<0, s>0$.

Assumption 3. $\partial k_{1}(s, a) / \partial s>0, s>0 ; \partial k_{2}(s, a) / \partial s<0, s<$ 0 .

Assumption 4. $\partial k_{j}(s, a) / \partial a<0, j=2-i$.
Assumption 1 says that the real market demand is impacted harder as intensity of the emergency is higher. Assumption 2 says that there are opposite influences of information under the different two types of emergencies. When $s<0$, more information will mitigate the decreasing demand situation; on the contrary, when $s>0$, more information will slow down the exaggerated increasing demand. Assumption 3 says that consumers' loss aversion psychological phenomenon is more obvious as intensity of the emergency is higher. When $s<0$, higher absolute value of $s$ stands for higher intensity of the emergency, and utility correction parameter $k_{2}$ decreases as $s$ increases. When $s>$ 0 , utility correction parameter $k_{1}$ increases as $s$ increases. Assumption 4 says that the consumers' loss aversion psychological phenomenon would be mitigated as they acquire more information. The utility correction parameters $k_{1}, k_{2}$ both decrease as the amount of information $a$ increases.

According to the above assumptions, we now proceed to analyze the supplier's information sharing strategies under different types of influences to the market by different emergencies and how the government price control impacts the supplier's decision-making behaviors. Recalling that we have derived the supplier's optimal production strategies and the optimal profit they can gain in Section 4, we can further analyze how those solutions vary when information is added into discussion. The supplier is rational and seeks to maximize profits. Naturally, we can learn the supplier's information sharing intentions by analyzing the optimal profits under different information amounts he puts into the market.

5.1. Information Sharing Strategies of the Supplier under Negative Emergency Impact. According to the four assumptions, the parameters $f, k_{1}, k_{2}$ are now functions about the sequential information $a$. Recalling that we have $v<c$ and $v \leq p$, we can derive the tendency of the optimal profit under $s<0$ on $a$.

By taking the first derivative of $\pi^{*}$ in (17) with respect to $a$, we can obtain

$$
\begin{aligned}
\frac{\partial \pi^{*}}{\partial a}=\frac{D}{4 r} & \cdot \frac{v\left(k_{2}(1-f)+f+1\right)+2 f r}{\left(k_{2}(1-f)+f+1\right)^{2}} \\
& \cdot\left[2\left(\left(k_{2}^{\prime}(1-f)-k_{2} f^{\prime}+f^{\prime}\right) v+2 f^{\prime} r\right)\right. \\
& \times\left(k_{2}(1-f)+f+1\right) \\
& -\left(\left(k_{2}(1-f)+f+1\right) v+2 f r\right) \\
& \left.\times\left(k_{2}^{\prime}(1-f)-k_{2} f^{\prime}+f^{\prime}\right)\right]>0 .
\end{aligned}
$$

In this situation, the supplier would choose to share information as the optimal profit is increasing according to information $a$. Under the same optimal conditions, the supplier can gain more profit from releasing information to the market. It is not hard to understand this phenomenon because more information appeases consumer risk perception which slows down the decreasing demand. 
5.2. Information Sharing Strategies of the Supplier under Positive Emergency Impact. Looking back to the analysis part in Section 4.2, the optimal solutions are divided into two sets because of the price cap ruled by the government. We analyze the supplier's information sharing strategies under different sets of solutions in this case.

When $d=q$, there exists no lost sales in the market; the supplier's profit function is given in (20). As described in (20), the supplier has different pricing and production decisions under different situations. When analyzing the supplier's information sharing strategies, there exist two interesting and important questions: whether the supplier has the incentive to share information when the price is at price cap and at what level of demand should the supplier share information. In order to find the supplier's best information sharing strategies, we need to divide the demand interval more specifically. The supplier's optimal conditions are described as follows:

$$
\begin{gathered}
p^{*}=p_{\text {no cap }}, \quad q^{*}=q_{\text {no cap }}, \text { if } p_{\text {no cap }} \leq \bar{p} ; \\
p^{*}=\bar{p}, \quad q^{*}=d=D \frac{2 f r+f k_{1} r-\left(1+f+f k_{1}\right) \bar{p}}{r}, \\
p^{*}=\bar{p}, \quad q^{*}=d=D \frac{2 f r+f k_{1} r-\left(1+f+f k_{1}\right) \bar{p}}{r}, \\
\text { if } p_{\text {nocap }}>\bar{p}, \tilde{q}<d \leq q_{T},
\end{gathered}
$$

where $\widetilde{q}=\left(\bar{p}-c+2 \xi q_{0}\right) / 2 \xi$.

Note that $\tilde{q}$ is the optimal supply quantity when the price is $\bar{p}$; we can derive $\widetilde{q}$ by setting price at $\bar{p}$ and solving the optimal profit in (23). Now we proceed to discuss the supplier's information sharing strategies under different market situations which is determined by the realized demand in (28).

If $p_{\text {no cap }} \leq \bar{p}$, the profit function is shown in (20) and the optimal price and production are given in (22). The first derivative of profit with respect to $a$ is as follows:

$$
\frac{\partial \pi}{\partial a}=p^{* \prime} q^{*}+2 \xi\left(\frac{p^{*}-c}{2 \xi}+q_{0}-q^{*}\right) q^{* \prime}<0 .
$$

The supplier's profit decreases as the amount of information increases; thus, he should not share information in this situation.

If $p_{\text {no cap }}>\bar{p}$ and $d \leq \tilde{q}$, price reaches price cap, and the first derivative of profit with respect to $a$ in this case is as follows:

$$
\frac{\partial \pi}{\partial a}=2 \xi\left(\frac{\bar{p}-c}{2 \xi}+q_{0}-q\right) q^{\prime}<0,
$$

where $\partial q / \partial a<0, \quad q \leq(\bar{p}-c) / 2 \xi+q_{0}$.

The supplier's profit decreases as the amount of information increases; thus, he should not share information in this situation.
If $p_{\text {no cap }}>\bar{p}$ and $\tilde{q}<d \leq q_{T}$, price reaches price cap, and the first derivative of profit with respect to $a$ in this case is as follows:

$$
\frac{\partial \pi}{\partial a}=2 \xi\left(\frac{\bar{p}-c}{2 \xi}+q_{0}-q\right) q^{\prime}>0,
$$

where $\partial q / \partial a<0,(\bar{p}-c) / 2 \xi+q_{0}<q<(\bar{p}-c+g) / 2 \xi+q_{0}$.

The supplier's profit increases as the amount of information increases; thus, he will share information to the market to suppress demand in this case, and the optimal situation is to drag demand back to the interval of $d \leq \widetilde{q}$ where he can maximize profit. In Appendix C, we show the proof in detail.

When $d>q$, there exists lost sales in the market; the marginal revenue of producing one more product is negative; thus, the supplier would rather undertake lost sales penalty. As illustrated in (26), the supplier's optimal production is constant at $q^{*}=\left(\bar{p}-c+g+2 \xi q_{0}\right) / 2 \xi$. In this case, the only factor that is affected by information is the realized demand $d$ in the profit function in (26). It is obvious that the supplier will share information to avoid lost sales penalty costs. We can prove this idea by looking at the first derivative of profit with respect to the amount of information shared to the market which is

$$
\frac{\partial \pi}{\partial a}=-d^{\prime} g>0
$$

where $\partial d / \partial a=(D / r)\left[f^{\prime} r+\left(f^{\prime}+f^{\prime} k_{1}+f k_{1}^{\prime}\right)(r-\bar{p})\right]<0$.

Obviously, the supplier's profit increases as the amount of information increases; the supplier will share all information without reservation.

\section{Numerical Example}

In this section, we present a series of numerical examples to explain the application and practical significance of the models. In the stable market, we specify the parameters as follows: $D=5000, \theta=0.5, r=50$, and $c=20$. Table 3 displays the sensitivity analysis of optimal results to consumers' need probability in the long-term equilibrium market. As shown in Table 1, the location of indifferent consumer draws closer to 1 as $\theta$ increases; the optimal price and profit increase as $\theta$ increases. When $\theta=1$, the maximum profit is $\pi=45000$. It is obvious that when consumers' perception of needing the product is higher, they are willing to pay higher prices for the product; then, the supplier can make more profit.

When emergencies happen, consumers' perception about their willingness to buy the product changes from the stable $\theta$ to $f$. And the existence of loss aversion phenomenon changes consumers' perception of utility; we use the utility correction parameters $k_{1}$ and $k_{2}$ to describe this change. The intensity of risk affects $f, k_{1}$, and $k_{2}$. Recalling that we have introduced the relationship between $f, k_{1}$, and $k_{2}$, without loss of generality we can further specify the exact functions as $f=1 /\left(1+0.9^{s}\right), k_{1}=10 /\left(1+3 \times 0.9^{s-2}\right)$, and $k_{2}=10 /(1+$ $\left.25 \times 1.1^{s+2}\right)$. Meanwhile, assume that the long equilibrium of the market is at $\theta=0.5, p_{0}=26.67, q_{0}=1000$, 
TABLE 3: Sensitivity of optimal results to the need probability in the stable market $(s=0)$.

\begin{tabular}{lcccc}
\hline$\theta$ & $x_{D}$ & $q_{0}$ & $p_{0}$ & $\pi$ \\
\hline 0 & - & - & - & - \\
0.1 & - & - & - & - \\
0.2 & - & - & - & - \\
0.3 & 0.04 & 200.00 & 21.54 & 307.69 \\
0.4 & 0.12 & 600.00 & 24.29 & 2571.43 \\
0.5 & 0.20 & 1000.00 & 26.67 & 6666.67 \\
0.6 & 0.34 & 1400.00 & 28.75 & 12250.00 \\
0.7 & 0.36 & 1800.00 & 30.59 & 19058.82 \\
0.8 & 0.44 & 2200.00 & 32.22 & 26888.89 \\
0.9 & 0.52 & 2600.00 & 33.69 & 35578.95 \\
1.0 & 0.60 & 3000.00 & 35.00 & 45000.00 \\
\hline
\end{tabular}

TABLE 4: Sensitivity of optimal results to the intensity of emergencies under $s<0$.

\begin{tabular}{lccccc}
\hline$s$ & $f$ & $k_{2}$ & $p^{*}$ & $q^{*}$ & $\pi^{*}$ \\
\hline-2 & 0.45 & 0.38 & 15.98 & 1822.57 & 5010.44 \\
-4 & 0.40 & 0.46 & 14.33 & 1562.13 & -430.84 \\
-6 & 0.35 & 0.55 & 12.66 & 1308.03 & -4984.35 \\
-8 & 0.30 & 0.66 & 11.03 & 1063.76 & -8583.43 \\
-10 & 0.26 & 0.79 & 9.51 & 831.65 & -11249.45 \\
-12 & 0.22 & 0.94 & 8.14 & 612.85 & -13077.06 \\
-14 & 0.19 & 1.12 & 6.95 & 407.41 & -14207.28 \\
-16 & 0.16 & 1.32 & 5.95 & 214.45 & -14797.31 \\
-18 & 0.13 & 1.55 & 5.13 & 32.41 & -14995.77 \\
-20 & 0.11 & 1.82 & - & - & - \\
\hline
\end{tabular}

and $\pi=6666.67$. The other parameters are described as $v=5, g=5, \xi=6$, and $\bar{p}=50$.

Then, we proceed to analyze the impact of different types of emergencies on the optimal results. Table 4 displays the sensitivity of optimal results to the intensity of risk under negative emergencies impact. As shown in Table $4, f$ and $k_{1}$ gradually reduce as the absolute value of $s$; that is, the intensity of negative emergencies increases, which leads to the reducing optimal price and sales quantity. Comparing Table 4 to Table 3, we could obtain that the negative emergency severely reduces demand, and the supplier has to cut price to avoid losses, but it never stops the decreasing sales and profit. The supplier will stop selling to the market when the price reaches the salvage value. Table 5 displays the sensitivity of optimal results to the intensity of risk under positive emergencies impact. As shown in Table $5, f$ and $k_{2}$ gradually increase as the value of $s$; that is, the intensity of positive emergencies increases which leads to an increasing demand, while the supply $\left(q^{*}\right)$ to the market and the profit gradually decrease as the intensity of emergencies increases. Comparing Table 5 to Table 3 , the supplier will rapidly expand production when the intensity of emergencies is relatively low but reduce production when it gets too high. This is because the price is gradually approaching the price cap regulated by the government, and the additional cost caused by extra
TABLE 5: Sensitivity of optimal results to the intensity of emergencies under $s>0$.

\begin{tabular}{lccccc}
\hline$s$ & $f$ & $k_{1}$ & $p^{*}$ & $q^{*}$ & $\pi^{*}$ \\
\hline 5 & 0.63 & 0.52 & 35.39 & 5989.14 & 62244.79 \\
10 & 0.74 & 0.85 & 40.33 & 3769.69 & 60013.22 \\
15 & 0.83 & 1.36 & 43.73 & 2628.10 & 52583.17 \\
20 & 0.89 & 2.10 & 45.90 & 2012.95 & 46062.10 \\
25 & 0.93 & 3.11 & 47.23 & 1670.26 & 41466.90 \\
30 & 0.96 & 4.33 & 48.03 & 1475.07 & 38493.73 \\
35 & 0.98 & 5.64 & 48.50 & 1362.31 & 36647.51 \\
40 & 0.99 & 6.87 & 48.77 & 1296.60 & 35525.74 \\
45 & 0.99 & 7.88 & 48.93 & 1258.10 & 34852.33 \\
50 & 0.99 & 8.63 & 49.03 & 1235.48 & 34450.84 \\
\hline
\end{tabular}

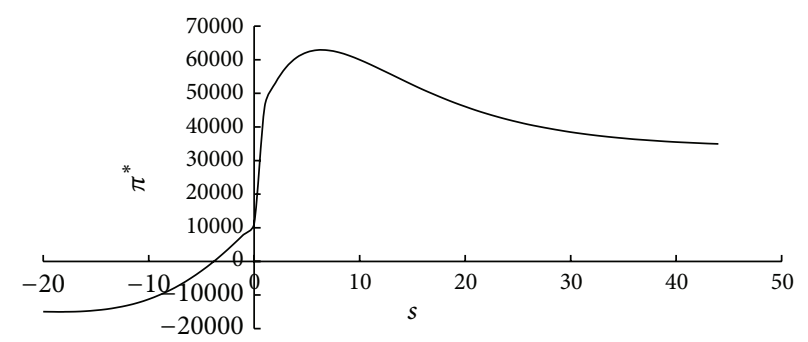

FIgURE 1: The impact of emergencies on profit.

production is convexly increasing. The profit is decreasing for the same reasons. Note that we only display the case when there exists no lost sales in the market, and the price is under price cap. In the case when the price reaches $\bar{p}$, the optimal supply to the market is constant at $q^{*}=1002.92$, and the profit decreases as the intensity increases; this is due to the increasing lost sales penalty cost.

We integrate numerical simulation results in Tables 4 and 5 and draw a linear graph in Figure 1 to depict the impact of emergencies on profit. As shown in Figure 1, when $s<0$, profit decreases as $s$ decreases and eventually stabilizes; when $s>0$, the profit line appears as an inverted-U shape; when it reaches its peak, profit declines and ultimately stabilizes as $s$ increases.

The supplier can circumvent the loss and get the maximum benefit through information sharing when emergencies happen. In order to depict the supplier's information sharing strategies under different types of emergencies, we assume that the information can be quantified and the supplier's complete information set is $A=\left\{a_{1}, a_{2}, a_{3} \cdots a_{100}\right\}$, which means that the supplier holds a total of 100 units of real, perfect, and nonredundant information. The supplier shares $a$ units of information to the market. Recalling that $f, k_{1}, k_{2}$ are functions on $a$ under a certain kind emergency, which means that in this case the intensity of emergency $s$ is constant, with the same analysis pattern as the last part (the sensitivity of optimal results to the intensity of emergencies), we draw four linear graphs in Figure 2 to depict the supplier's information sharing intensions under different types of emergencies (negative or positive). 
A certain kind of negative emergency occurs and its intensity is $=-13$, and we specify the exact functions of $f$ and $k_{2}$ as $f=0.2+a / 500, k_{2}=0.2-a / 500$ without loss of generality. Then, calculate the profit under different amount of information and draw the linear graph in Figure 2. As shown in Figure 2, the profit increases as the amount of information shared to the market increases under negative emergency impact $(s<0)$. Obviously, when a certain negative emergency occurs, the supplier will share all information without reservation in order to eliminate subjective risk, but it is impossible to eliminate all risk (objective risk).

When a certain positive emergency happens, the supplier's information sharing strategies will be much more diversified as illustrated in the analytical model in Section 5.2. When a certain positive emergency happens and its intensity is $s=8$, there exists no lost sales, the price is under price cap, and we specify the exact functions of $f$ and $k_{1}$ in this case as $f=0.7-a / 350, k_{1}=2.5-a / 500$ without loss of generality. As shown in Figure 2, the profit decreases as the amount of information increases. In this case, the supplier has no incentive to share information. When the intensity of the emergency is $s=16$, the demand reaches $d_{T}$, and we specify the exact functions of $f$ in this case as $f=$ $0.85-a / 300$ without loss of generality. Figure 2 illustrates that the profit curve appeared as an inverted- $\mathrm{U}$ and there exists a maximum profit. Thus, the supplier will share some amount of information to maintain high level profits. When the intensity of the emergency is $s=40$, the demand exceeds $d_{T}$, there exists lost sales, and we specify the exact functions of $f$ in this case as $f=1-a / 250$ without loss of generality. As shown in Figure 2, the profit increases as the amount of information increases. This is because the added cost of production is bigger than lost sales penalty; the supplier will share information to reduce demand.

\section{Concluding Remarks}

This paper studies the impact of emergencies on the supplier's decision-making behaviors including production and information sharing with the consideration of consumers' loss aversion psychological phenomenon under government price control. The intensity of emergencies is sequential and emergencies can be divided into two types (positive or negative) according to their effect (increasing or reducing) on demand. In addition to the real disruption caused by emergencies, consumers have subjectively risk distorted perception about how much they need the product which makes demand abnormally diverged from that in the stable market. Information is very effective to appease consumers' subjectively risk distorted perception. The government regulates the market through price control which is constant during the selling season. The supplier is supposed to have real, perfect, and nonredundant information; he can manipulate demand by deciding the amount of information to share with the market. When emergencies have negative effect on demand, the supplier's sales will reduce and he would share information to the market because the optimal profit increases along with the amount of information. In reality, real information will

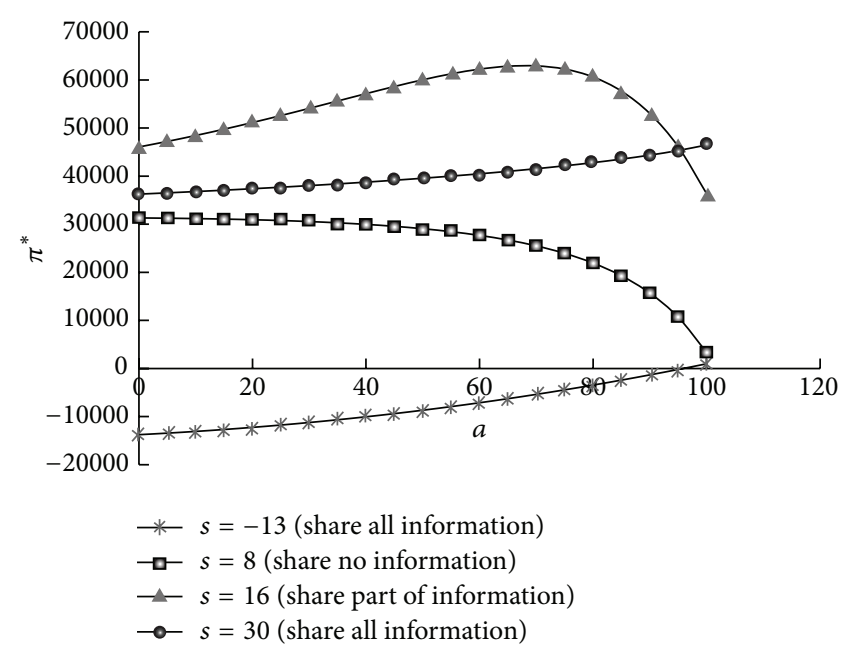

FIGURE 2: The impact of information sharing on profit.

increase the demand because it alleviates consumers' uncertainty about the market, which increases demand. When emergencies have positive effect on demand, we exclude the situation when the supplier purposefully reduces supply to the market; then, the supplier's production decisions are divided into two situations (there exists no lost sales and there exists lost sales) which are determined by the government price control. We, respectively, solve the optimal production decisions under the two situations. The price cap plays an important role in determining the position of the supplier's marginal cost breakeven point. We have derived the supplier's optimal production decisions under different situations, and we found that when the price is under price cap the supplier will not share information to the market; when the price reaches price cap, the supplier will share a certain amount of information to the market. We were surprised to find that increasing demand is not always good for the supplier when there exist government price control and lost sales penalty, and information helps the supplier to effectively suppress the abnormally increasing demand.

This paper makes an initial attempt to study the supplier's decision making behaviors of choosing the right risk strategies including production and information sharing and presents a series of managerial perceptions of emergencies. Our results of the supplier's information sharing strategies provide suggestions about how to deal with consumer panic for emergencies. The biggest obstacle in studying consumer behaviors is due to the issue of modeling consumer risk perception. Using Hotelling model to derive consumer demand with risk perception is one way to resolve this issue. Although we only study a simple model with one monopoly supplier and end consumers, the approach we use should be applicable to more general situations. Interesting extensions may include retailers, forward information sharing from supplier to retailer. There is also much room for further improvement, such as considering government as a player who participates in the game to regulate the market by changing price caps and putting information to the market. When there are multiperiod selling seasons and return is allowed, the supplier's 
production and information sharing strategies should be much different, which is worth investigating as well.

\section{Appendices}

\section{A. The Supplier's Profit Function under Negative Emergency Impact}

The supplier's complete profit function can be write as

$$
\pi= \begin{cases}p q-q_{0} c+\left(q_{0}-q\right) v, & q<q_{0} \\ p q-q c-\zeta\left(q-q_{0}\right)^{2}, & q \geq q_{0}\end{cases}
$$

where $d=D\left(2 f r-\left(1+f+k_{2}-f k_{2}\right) p\right) / r$. Now we can discuss whether the supplier has the incentive to expand production supply more to the market comparing with $q_{0}$ while the demand is decreasing when there exists no lost sales for the supplier; that is, $d=q$. Suppose that the demand in this situation reaches $q_{0}$; that is $d=q_{0}$. Then, we can derive the price $\breve{p}$ by substituting (9) into (15), which is

$$
\breve{p}=\frac{c+4 f r+c \theta-2 r \theta}{2\left(1+f+k_{2}-f k_{2}\right)} .
$$

Then, we can further discuss the supplier's decision by analyzing its marginal income. If $\breve{p}<c$, apparently the supplier has no incentive to expand production; thus, $q<q_{0}$. If $\breve{p} \geq c$, the supplier may or may not expand production which needs to be further discussed. In order to further discuss the supplier's choices when $\breve{p} \geq c$, we can get a general understanding of the profit curve by solving the first and second order conditions, which are

$$
\begin{aligned}
\frac{\partial \pi}{\partial q} & =-c-\frac{2(-D f+q) r}{D\left(1+f+k_{2}-f k_{2}\right)}+2\left(q_{0}-q\right) \zeta \\
\frac{\partial^{2} \pi}{\partial q^{2}} & =-\frac{2 r}{D\left(1+f+k_{2}-f k_{2}\right)}-2 \zeta<0 .
\end{aligned}
$$

Equation (A.3) shows that the second derivative of $\pi$ with respect to $q$ is negative, and the profit curve should be concave. By substituting $q_{0}$ which is expressed in (9) into the first derivative of $\pi$ with respect to $q$, we can have

$$
\left.\frac{\partial \pi}{\partial q}\right|_{q=q_{0}}=\frac{c\left(f+k_{2}-f k_{2}-\theta\right)+2 r(-f+\theta)}{-1+f\left(-1+k_{2}\right)-k_{2}}<0 .
$$

Equation (A.4) shows that the first derivative of $\pi$ with respect to $q$ is negative when $q=q_{0}$, recalling that the profit curve is concave; then, the maximum should be at some $q^{*}$ which satisfies $q^{*}<q_{0}$. Then, the supplier has no incentive to expand production under negative emergency impact.

\section{B. The Supplier's Profit Function under Positive Emergency Impact}

The supplier's complete profit function can be write as

$$
\pi= \begin{cases}p q-q_{0} c+\left(q_{0}-q\right) v, & q<q_{0} \\ p q-q c-\zeta\left(q-q_{0}\right)^{2}-(d-q) g, & \\ d_{T} \geq \frac{\bar{p}-c+g+2 \zeta q_{0}}{2 \zeta}, & q \geq q_{0}, \\ p q-q c-\zeta\left(q-q_{0}\right)^{2}, & \\ d_{T}<\frac{\bar{p}-c+g+2 \zeta q_{0}}{2 \zeta}, & \end{cases}
$$

where $d_{T}=D\left(\left(2 f r+f k_{1} r-\left(1+f+f k_{1}\right) \bar{p}\right) / r\right), q_{T}=(\bar{p}-c+g+$ $\left.2 \zeta q_{0}\right) / 2 \zeta$, and $d=x_{D}, D=D\left(\left(2 f r+f k_{1} r-\left(1+f+f k_{1}\right) p\right) / r\right)$.

When the supplier purposefully reduces supply $q$, in this case $q$ represents the sales quantity, and $q_{0}$ is supposed to be producing before the selling season. Then, the profit function is

$$
\pi=p q-q_{0} c+\left(q_{0}-q\right) v, \quad q<q_{0},
$$

where $d=D\left(\left(2 f r+f k_{1} r-\left(1+f+f k_{1}\right) p\right) / r\right)$.

Now we can discuss whether the supplier has the incentive to reduce supply comparing with $q_{0}$ while the demand is increasing, when there exists no lost sales in the market; that is, $d=q$. Suppose that the supplier supplies $q_{0}$ to the market, and in order to sale out all the $q_{0}$ units of products, the supplier should price at $\widehat{p}$ which can be derived by solving $p$ when $d=q_{0}$. In this situation, the demand is satisfied and the supplier has no leftover at price $\widehat{p}$. Then, we can derive the price $\widehat{p}$ by substituting (9) into the realized demand function in (18), which is

$$
\widehat{p}=\frac{c+2 f\left(2+k_{1}\right) r+c \theta-2 r \theta}{2\left(1+f+f k_{1}\right)} .
$$

We can get a general understanding of the profit curve by solving the first and second order conditions, which are

$$
\begin{aligned}
\frac{\partial \pi}{\partial q} & =\frac{\left(D f\left(2+k_{1}\right)-2 q\right) r}{D\left(1+f+f k_{1}\right)}-v ; \\
\frac{\partial^{2} \pi}{\partial q^{2}} & =-\frac{2 r}{D\left(1+f+f k_{1}\right)}<0 .
\end{aligned}
$$

Note that the second derivative of the profit function with respect to $q$ is negative; then, we can further analyze values of the first derivative at the two extreme points $\left\{0, q_{0}\right\}$, which are

$$
\begin{aligned}
& \left.\frac{\partial \pi}{\partial q}\right|_{q=q_{0}}=\frac{c+f\left(2+k_{1}\right) r-\left(1+f+f k_{1}\right) v+c \theta-2 r \theta}{1+f+f k_{1}}>0 ; \\
& \left.\frac{\partial \pi}{\partial q}\right|_{q=0}=\frac{f r\left(2+k_{1}\right)}{1+f+f k_{1}}+v>0 .
\end{aligned}
$$

As shown in (B.5), at the left hand side extreme point the first derivative is positive, and at the right hand extreme point 
the first derivative is also positive. Recalling that the profit curve is concave, thus, it is not hard to understand that the supplier's profit can be improved by supplying more than $q_{0}$ to the market. Thus, we can exclude the situation that the supplier may purposefully control supply to the market.

\section{Proof}

The first derivatives of the optimal price and production in (22) with respect to $a$ are given as

$$
\begin{aligned}
\frac{\partial p^{*}}{\partial a}=m^{\prime}((c r & +r \frac{r f^{\prime} n+r f k_{1}^{\prime}}{m^{\prime}}+2 r \xi\left(D f n-q_{0}\right) \\
& +2 D m \xi \frac{r f^{\prime} n+r f k_{1}^{\prime}}{m^{\prime}} \\
& \left.-2 p^{*} r-4 p^{*} D m \xi\right) \\
& \left.\times(2 m(r+D m \xi))^{-1}\right)<0 .
\end{aligned}
$$

is

The first derivative of $q$ when price is $\bar{p}$ with respect to $a$

$$
\frac{\partial q}{\partial a}=\frac{D}{r}\left[f^{\prime} r+\left(f^{\prime}+f^{\prime} k_{1}+f k_{1}^{\prime}\right)(r-\bar{p})\right]<0,
$$

where $q \leq(\bar{p}-c) / 2 \xi+q_{0}$.

The first derivative of $q$ when price is $\bar{p}$ with respect to $a$ is

$$
\frac{\partial q}{\partial a}=\frac{D}{r}\left[f^{\prime} r+\left(f^{\prime}+f^{\prime} k_{1}+f k_{1}^{\prime}\right)(r-\bar{p})\right]<0,
$$

where $(\bar{p}-c) / 2 \xi+q_{0}<q<(\bar{p}-c+g) / 2 \xi+q_{0}$.

\section{Conflict of Interests}

The authors declare that there is no conflict of interests regarding the publication of this paper.

\section{Acknowledgments}

This research was supported by National Natural Science Foundation of China (Grant nos. 71271199 and 70901067), Program for New Century Excellent Talents in University (Grant no. NCET-13-0538), Science Fund for Creative Research Groups of China (Grant no. 71121061), and the Fundamental Research Funds for the Central Universities of China (no. WK2040160008).

\section{References}

[1] M. Christopher and H. Lee, "Mitigating supply chain risk through improved confidence," International Journal of Physical Distribution \& Logistics Management, vol. 34, no. 5, pp. 388396, 2004.
[2] S.-H. Kim, M. A. Cohen, S. Netessine, and S. Veeraraghavan, "Contracting for infrequent restoration and recovery of mission-critical systems," Management Science, vol. 56, no. 9, pp. 1551-1567, 2010.

[3] S. M. Tom, C. R. Fox, C. Trepel, and R. A. Poldrack, "The neural basis of loss aversion in decision-making under risk," Science, vol. 315, no. 5811, pp. 515-518, 2007.

[4] A. Bruhin, H. Fehr-Duda, and T. Epper, "Risk and rationality: uncovering heterogeneity in probability distortion," Econometrica, vol. 78, no. 4, pp. 1375-1412, 2010.

[5] U. M. Dholakia, "A motivational process model of product involvement and consumer risk perception," European Journal of Marketing, vol. 35, no. 11-12, pp. 1340-1362, 2001.

[6] T. M. Alessandri, "Risk and procedural rationality: a behavioral theory perspective," Journal of Strategy and Management, vol. 1, no. 2, pp. 198-217, 2008.

[7] F. Y. Chen and C. A. Yano, "Improving supply chain performance and managing risk under weather-related demand uncertainty," Management Science, vol. 56, no. 8, pp. 1380-1397, 2010.

[8] Z. Yang, G. Aydin, V. Babich, and D. R. Beil, "Supply disruptions, asymmetric information, and a backup production option," Management Science, vol. 55, no. 2, pp. 192-209, 2009.

[9] D. Kahneman and A. Tversky, "Prospect theory: an analysis of decision under risk," Econometrica, vol. 47, no. 2, pp. 263-291, 1979.

[10] A. Tversky and D. Kahneman, "Loss aversion in riskless choice: a reference-dependent model," The Quarterly Journal of Economics, vol. 106, no. 4, pp. 1039-1061, 1991.

[11] M. Abdellaoui, H. Bleichrodt, and C. Paraschiv, "Loss aversion under prospect theory: a parameter-free measurement," Management Science, vol. 53, no. 10, pp. 1659-1674, 2007.

[12] M. Abdellaoui, H. Bleichrodt, and O. L'Haridon, "A tractable method to measure utility and loss aversion under prospect theory," Journal of Risk and Uncertainty, vol. 36, no. 3, pp. 245266, 2008.

[13] C. Camerer, "Individual decision making," in The Handbook of Experimental Economics, J. H. Kagel and A. E. Roth, Eds., pp. 587-703, Princeton University Press, Princeton, NJ, USA, 1995.

[14] U. Schmidt and S. Traub, "An experimental test of loss aversion," Journal of Risk and Uncertainty, vol. 25, no. 3, pp. 233-249, 2002.

[15] L. Goette, D. Huffman, and E. Fehr, "Loss aversion and labor supply," Journal of the European Economic Association, vol. 2, no. 2-3, pp. 216-228, 2004.

[16] R. Jarrow and F. Zhaou, "Downside loss aversion and portfolio management," Management Science, vol. 52, no. 4, pp. 558-566, 2006.

[17] J. Nasiry and I. Popescu, "Dynamic pricing with loss-averse consumers and peak-end anchoring," Operations Research, vol. 59, no. 6, pp. 1361-1368, 2011.

[18] X. Qi, J. F. Bard, and G. Yu, "Supply chain coordination with demand disruptions," Omega, vol. 32, no. 4, pp. 301-312, 2004.

[19] X. Gan, S. P. Sethi, and H. Yan, "Coordination of supply chains with risk-averse agents," in Supply Chain Coordination under Uncertainty, pp. 3-31, Springer, Berlin, Germany, 2011.

[20] C. X. Wang and S. Webster, "The loss-averse newsvendor problem," Omega, vol. 37, no. 1, pp. 93-105, 2009.

[21] M. E. Schweitzer and G. P. Cachon, "Decision bias in the newsvendor problem with a known demand distribution: experimental evidence," Management Science, vol. 46, no. 3, pp. 404-420, 2000. 
[22] X. Chen, M. Sim, D. Simchi-Levi, and P. Sun, "Risk aversion in inventory management," Operations Research, vol. 55, no. 5, pp. 828-842, 2007.

[23] C. X. Wang and S. Webster, "Channel coordination for a supply chain with a risk-neutral manufacturer and a loss-averse retailer," Decision Sciences, vol. 38, no. 3, pp. 361-389, 2007.

[24] W. J. Marshall, J. B. Yawitz, and E. Greenberg, "Optimal regulation under uncertainty," The Journal of Finance, vol. 36, no. 4, pp. 909-921, 1981.

[25] S. Cowan, "Optimal risk allocation for regulated monopolies and consumers," Journal of Public Economics, vol. 88, no. 1-2, pp. 285-303, 2004.

[26] M. N. Faisal, D. K. Banwet, and R. Shankar, "Supply chain risk mitigation: modeling the enablers," Business Process Management Journal, vol. 12, no. 4, pp. 535-552, 2006.

[27] L. Li, "Information sharing in a supply chain with horizontal competition," Management Science, vol. 48, no. 9, pp. 1196-1212, 2002.

[28] A. Ghadge, S. Dani, and R. Kalawsky, "Supply chain risk management: present and future scope," International Journal of Logistics Management, vol. 23, no. 3, pp. 313-339, 2012.

[29] H. Hotelling, "Stability in competition," The Economic Journal, vol. 39, no. 153, pp. 41-57, 1929.

[30] G. P. Cachon, "Supply chain coordination with contracts", in Handbooks in Operations Research and Management, vol. 11 of Supply Chain Management: Design, Coordination and Operation, pp. 227-339, 2003. 


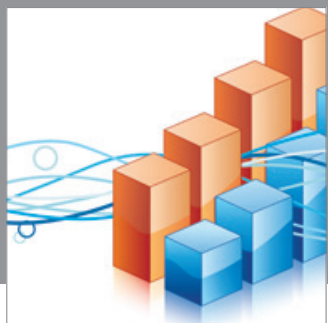

Advances in

Operations Research

mansans

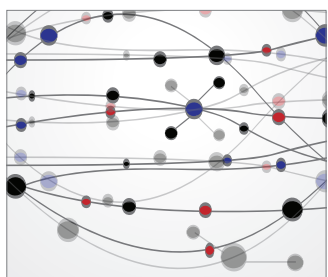

The Scientific World Journal
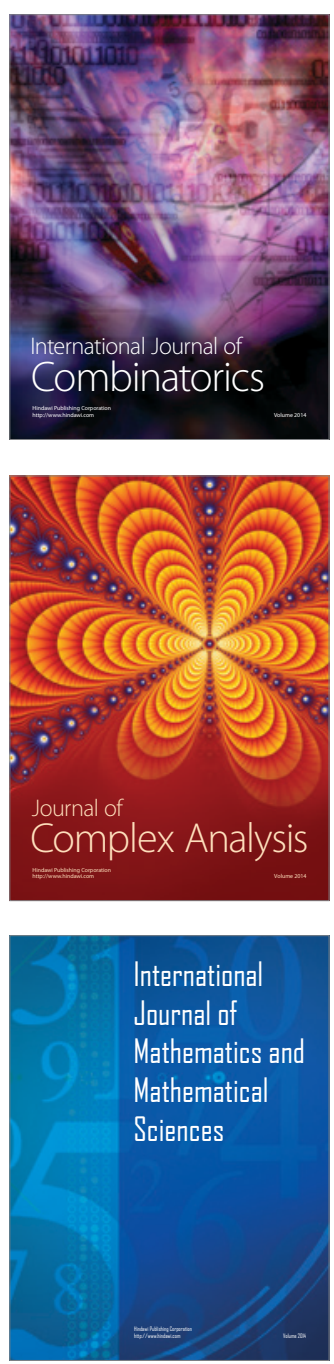
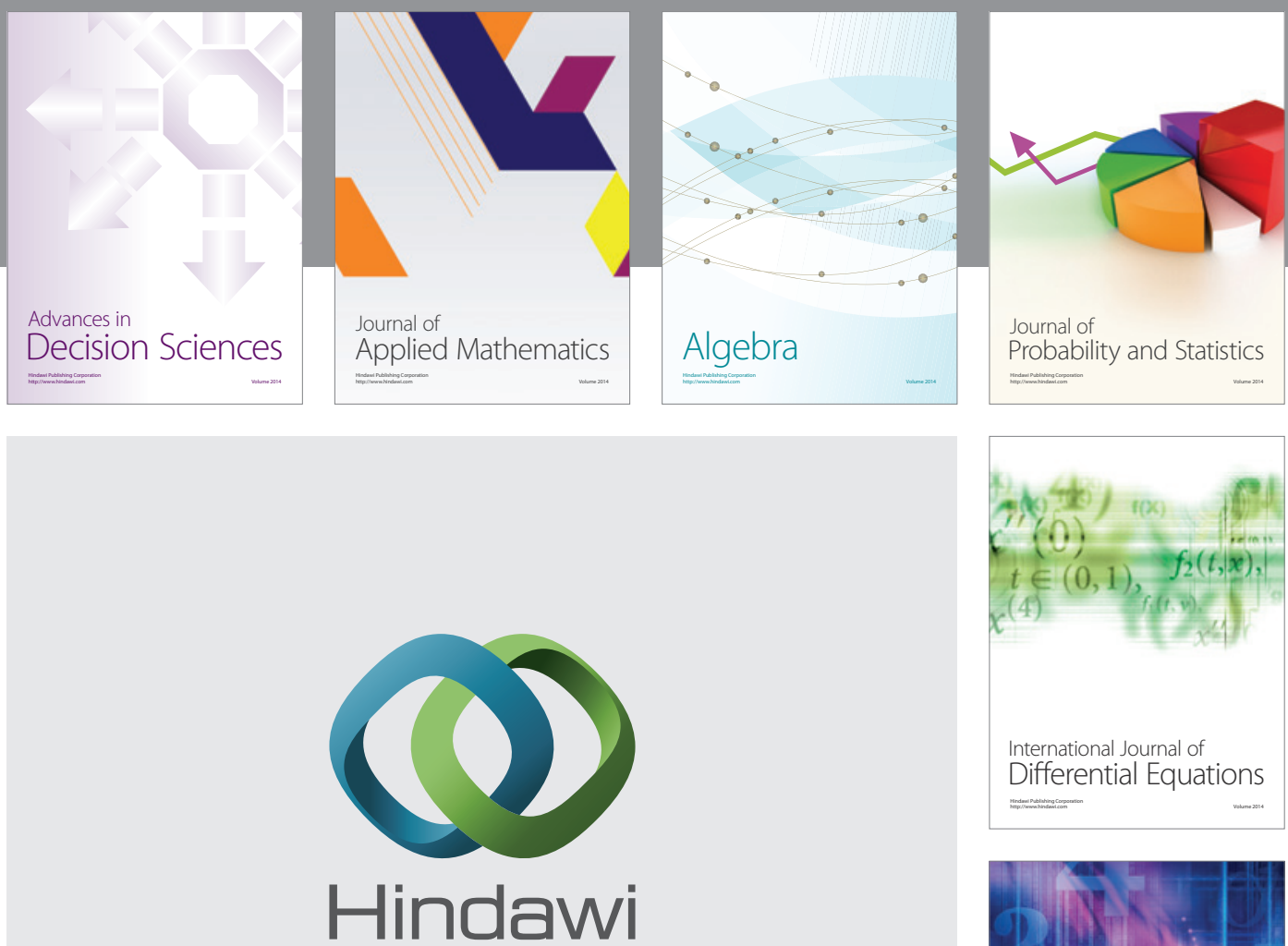

Submit your manuscripts at http://www.hindawi.com
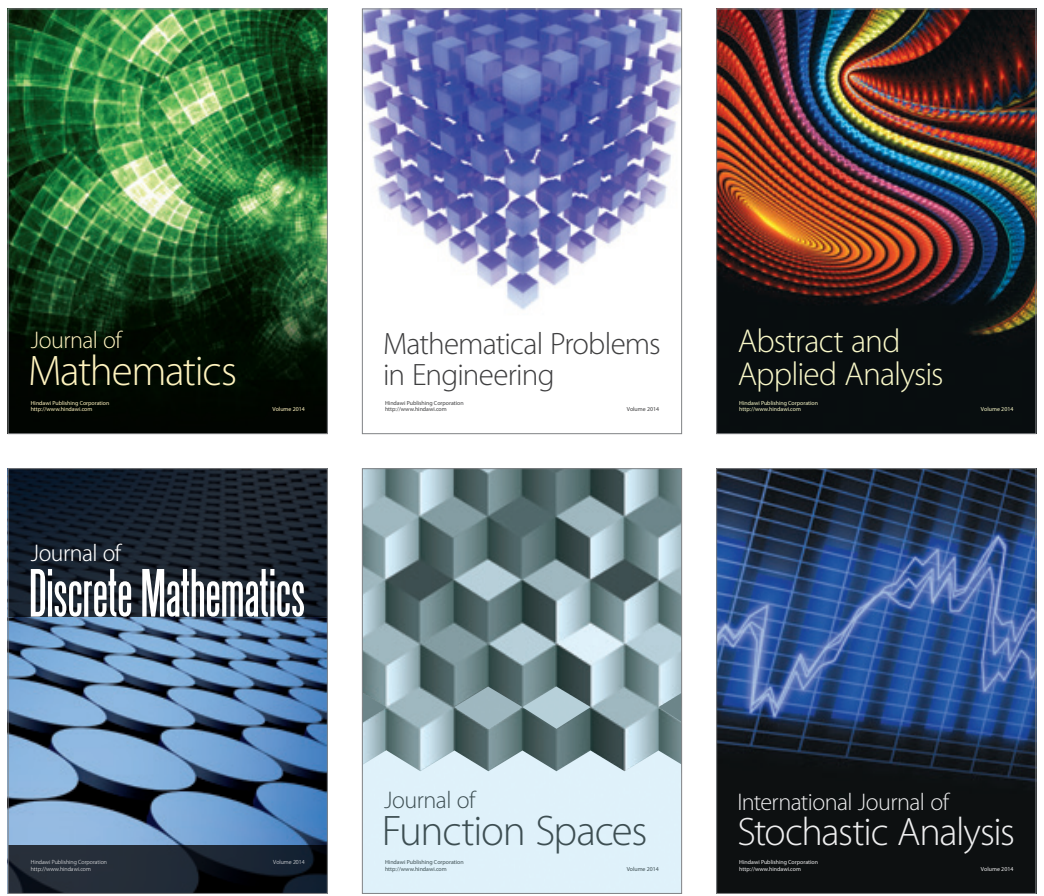

Journal of

Function Spaces

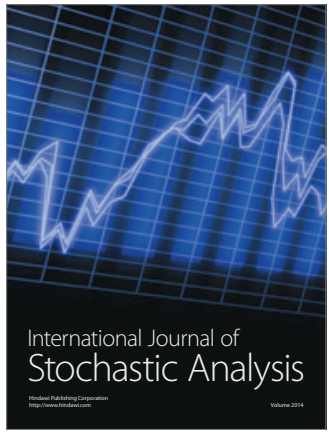

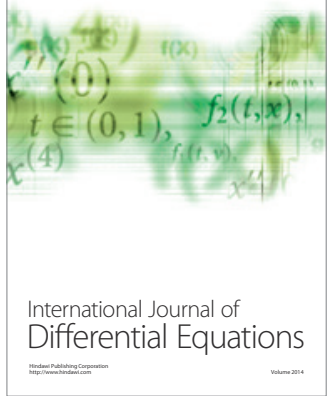
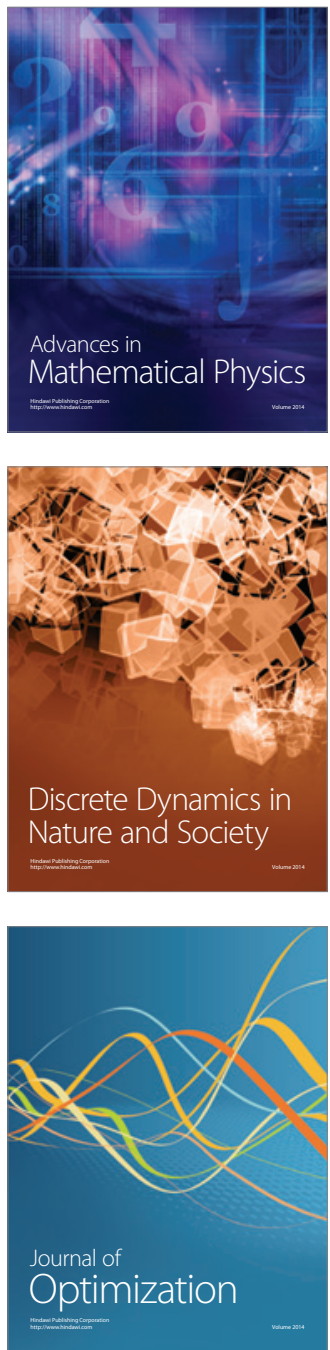